\title{
Quantifying changes of wind speed distributions in the historical record of Atlantic tropical cyclones
}

\author{
K. Chen ${ }^{1}$, J. McAneney ${ }^{1}$, and K. Cheung ${ }^{2}$ \\ ${ }^{1}$ Risk Frontiers - Natural Hazards Research Centre, Macquarie University, NSW 2109, Australia \\ ${ }^{2}$ Department of Environment \& Geography, Macquarie University, NSW 2109, Australia
}

Received: 26 November 2008 - Revised: 15 October 2009 - Accepted: 15 October 2009 - Published: 30 October 2009

\begin{abstract}
Here we re-examine the official Atlantic basin tropical cyclone (hurricane) database HURDAT (1851-2008) and quantify differences between wind speed distributions in the early historical (1851-1943) record and more recent observations. Analyses were performed at three different geographical levels: for all six-hourly track segments of all Atlantic basin events, all segments of all events that crossed the US mainland, and US landfalling segments alone. At all three geographical levels of study, distributions of windspeeds over the last two, four and six decades display negligible dispersion or systematic change over time. On the other hand and relative to wind speed frequencies for subsequent years, the 1851-1943 record has a marked and statistically significant over-representation of wind speeds largely corresponding to Saffir-Simpson Categories 1 and 2 and underrepresentation of Categories 4 and 5 events; importantly, no single Category 5 event is recorded prior to 1924. The stability of the distribution of windspeeds at landfall over the last six decades, the dataset in which we can have most confidence, suggests that the differences in the earlier record are most likely explained by well-known measurement and observational deficiencies. Moreover by disaggregating the Power Dissipation Index (PDI), we demonstrate that the upward trend in Atlantic basin PDI since 1970s does not imply stronger and longer duration Category 5 windspeeds despite a warming climate. These results have implications for hurricane catastrophe loss modeling for the insurance industry and long-term trend analyses of the historical wind speed record, especially those related to the attribution of the role of Global Climate Change.
\end{abstract}

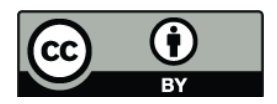

Correspondence to: K. Chen (kchen@els.mq.edu.au)

\section{Introduction}

Many factors condition prices for international catastrophe reinsurance. Of special concern are geographical combinations of exposure and hazards having the capacity to generate extreme losses. One such risk is posed by US hurricanes (Tropical Cyclones, TCs) that have accounted for seven of the top ten most costly insurance event losses since 1970 (Swiss Re, 2009). It is unsurprising therefore that recent active North Atlantic TC seasons and rising insurance and economic losses have stimulated more research on TCs and especially their potential link to a warming climate (Webster et al., 2005; Pielke et al., 2005; Goldenberg et al., 2001). This research includes the attribution of sea surface temperatures and other variables to increasing tropical cyclone intensity (Hoyos et al., 2006; Saunders and Lea, 2008); projection of frequency and intensity changes using climate models (Emanuel et al., 2008; Knutson et al., 2008); reconstruction of prehistoric evidence for major TCs from paleo-sediment records (Liu, 2007; Nyberg et al., 2007); and re-examination and improvements of existing TC databases (Landsea, 2007; Kossin et al., 2007; Chenoweth and Divine, 2008). Our research provides further documentary evidence of the incompleteness of the early historical record of the Atlantic TC windspeed database and does so in a manner different to that which has been published previously.

It is generally agreed that with the advent of aircraft reconnaissance in 1944, geostationary satellite imagery in 1966 and the development of the Dvorak intensity estimation technique since 1972 (Velden et al., 2006), the more recent TC record is more reliable than the earlier record. Early TC records are mainly derived from shipboard observations and/or measurements far less sophisticated than what is available today and so it comes as no surprise that the merging of these with more recent measurements may not result in a homogeneous time series. While the limitations, inconsistencies and biases of wind speed estimates and their provenance

Published by Copernicus Publications on behalf of the European Geosciences Union. 
in the early historical record are well known (e.g. Jarvinen et al., 1984; Landsea et al., 2004, 2006, 2008, 2009; Landsea, 2005, 2007; Blake et al., 2007), little has been reported about wind speed distributions at differing geographical and temporal scales. The issue is important since the wind speeds are used to calculate TC energy metrics such as the Power Dissipation Index (PDI) (Emanuel, 2005), and moreover their distributions underpin TC catastrophe loss modeling (e.g. Watson and Johnson, 2004; Lonfat et al., 2007; Grossi and Kunreuther, 2005) as commonly used by the insurance industry to inform premium pricing, reinsurance rates and capital retentions. Our analysis serves as a further warning to readers that any conclusions drawn from or applications based upon inherently low-quality wind speed estimates should be treated with caution.

\section{Data and analysis}

We analysed the most recent form of the official Atlantic basin tropical cyclone database HURDAT through the US National Hurricane Center (http://www.nhc.noaa.gov/ pastall.shtml, data file updated 14 May 2009). This version of HURDAT contains details of 1410 events (including 560 tropical storms and 850 hurricanes) for the period 1851-2008, and covers the Atlantic Ocean, Gulf of Mexico and Caribbean Sea. Event details are recorded at sixhourly "best-track" segments and include Year, Month, Day, Hour, Name, latitude, longitude, storm movement speed and direction, wind speed and, where available, central pressure. The HURDAT has been used in many previous studies (e.g. Chang and Guo, 2007; Solow and Beet, 2008; Vecchi and Knutson, 2008).

Windspeed estimates in the database refer to maximum sustained surface wind speeds at the conventional measurement height of $10 \mathrm{~m}$. For analysis, we focus on track segments with wind speeds at least of tropical storm strength ( $\geq 34$ knots). Wind speed descriptions in this paper follow the Saffir-Simpson Hurricane Scale: Category 1 (wind speed range 64-82 knots), Category 2 (83-95 knots), Category 3 (96-113 knots), Category 4 (114-135 knots) and Category 5 ( $\geq 136$ knots). Categories 3 to 5 events are referred to as major TCs and Categories 4 and 5 as extreme.

We group the HURDAT record into two parts: the first comprises the early historical period (1851-1943) and the second, the most recent six decades (1947-2006), which we further sub-divide into three 20 -year time series and excluding the three years in between. We examine wind speed distributions at three geographical levels of study, each having varying numbers of samples (i.e. track segments with Categories 1-5 wind speeds, 1851-2008): segments for all events in the entire Atlantic basin (14003 segments, Fig. 1a), segments for all events that eventually crossed the United States' mainland (5125 segments, Fig. 1c), and US landfalling segments that crossed the coast from ocean to land including multiple landfalling segments of a single event (350 segments, Fig. 1e). This hierarchy of groupings is based on the presumption that as the region of study becomes more geographically constrained then the early historical wind estimates might have been better observed. In what follows, we first report wind speed distributions for the three levels of analysis.

\section{Wind speed distributions at three geographical levels}

Unlike previous studies that only reported aggregate statistics on the annual number of hurricanes or major hurricanes, we first stratify the annual number of tropical storms and hurricanes by Saffir-Simpson Hurricane categories (Fig. 2). Some patterns are evident: first, while the number of tropical storms appears to be increasing with time, no such trend is obvious for Categories 1, 2, and 3. Secondly and more particularly, no single Category 5 TC is listed prior to 1924, a result which clearly illustrates the limitations of the database: if the average frequency of Category 5 TCs during 1924-2008 were to be representative of the entire record, there should have been about 28 Category 5 TCs during the period 18511923. Lastly, and less dramatically than for Category 5 TCs, the number of Category 4 TCs during 1851-1943 (33 Category 4 TCs) is also clearly less than that recorded post-1944 (68 Category $4 \mathrm{TCs}$ ). We will return to these points in later discussion.

Instead of using discrete TC categories, Fig. 1b shows the same wind speed data (Categories 1-5) plotted as the frequency for the four periods - 1851-1943, 1947-2006, 19672006, and 1987-2006. Wind speed distributions from the past two, four and six decades show little difference. Relative to the recent six decades, however, the period 18511943 exhibits an apparent overestimation in the frequency of wind speeds in the range 70-90 knots (largely corresponding to Categories 1 and 2 TCs) and an underestimation in wind speeds beyond 110 knots (largely Categories 4 and 5 TCs).

We now turn our attention to all track segments of the TCs that ultimately crossed the US mainland. From Fig. 1d, it is even more apparent that while there is little variation in the wind speed distributions over the past two, four and six decades, the 1851-1943 record is again inconsistent with more recent observations. In the early historical record, there is a significant relative over-representation in the wind speed range 70-90 knots compared with the post-1947 data and a relative under-representation for wind speed of Categories 4 and 5 TCs.

Let's now focus on the subset of US landfalling segments, observations in which we might expect to have greatest confidence. From Fig. 1f, the distributions over the past two, four and six decades are again closely matched although the variability is understandably increased with the smaller sample size. The distribution of wind speeds for the 18511943 period remains distinctively different and is once again 
(a)

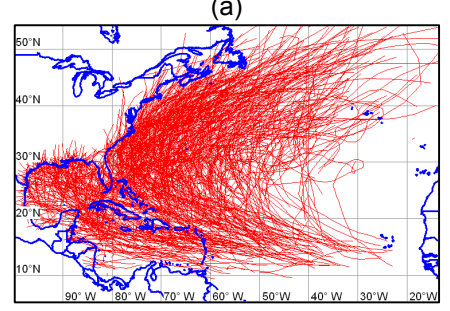

(c)

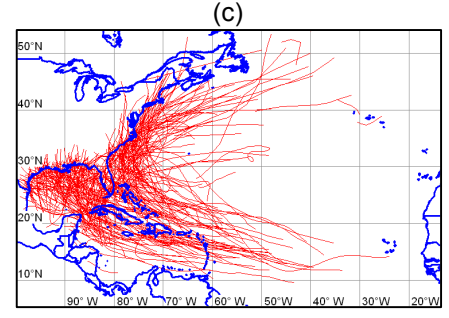

(e)

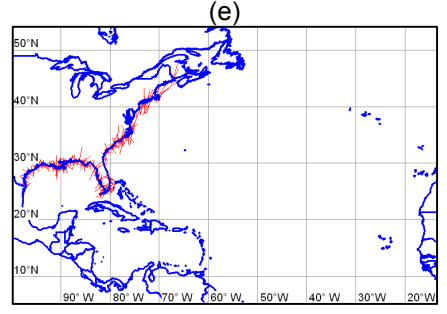

(b)

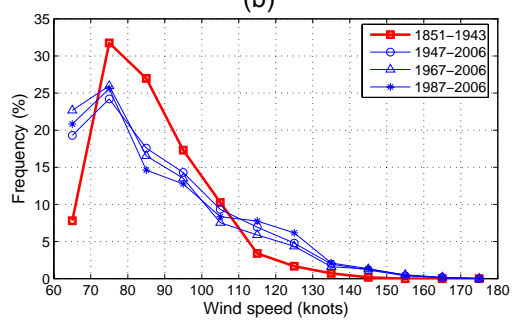

(d)

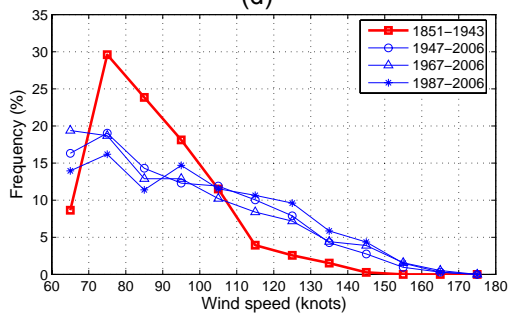

(f)

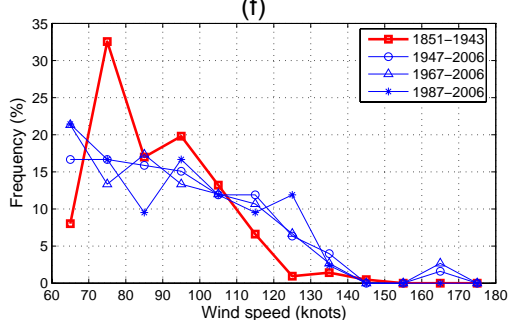

Fig. 1. Atlantic TC track segments (Categories 1-5 wind speeds, 1851-2008) at three geographical scales and associated wind speed distributions for four historical periods selected: 1851-1943, 1947-2006, 1967-2006, and 1987-2006. (a) All segments of all Atlantic basin TCs. (b) Wind speed distributions for (a). (c) All segments of all TCs that crossed the US mainland. (d) Wind speed distributions for (c). (e) US landfalling segments. (f) Wind speed distributions for (e).

(a)

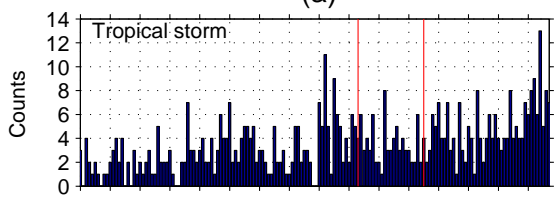

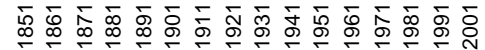

(c)

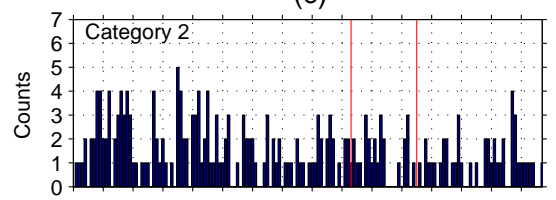

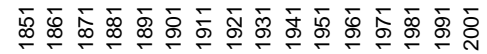

(e)

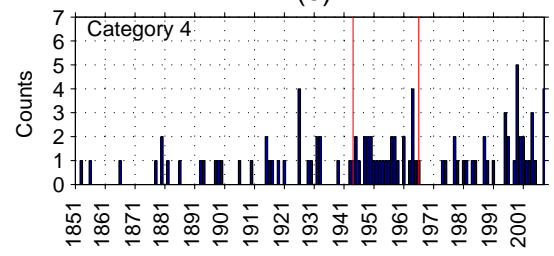

Year (b)

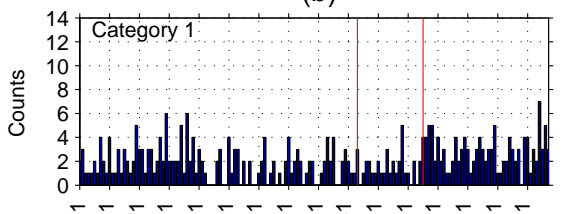

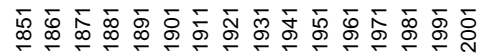

(d)

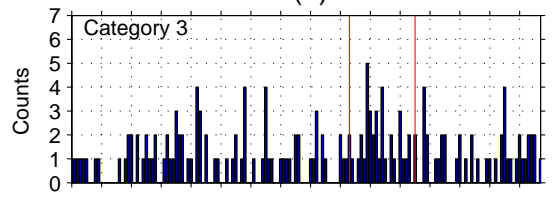

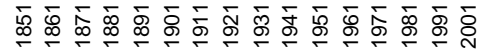

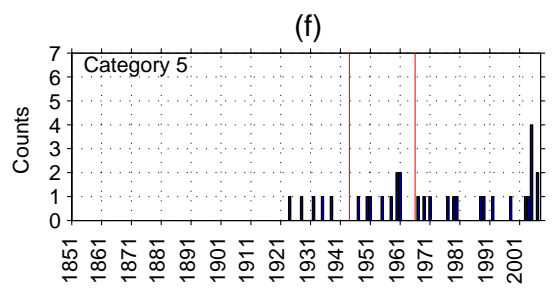

Year

Fig. 2. Annual number of Atlantic tropical storms and hurricanes (1851-2008) by Saffir-Simpson Hurricane categories. (a) Tropical storms. (b) Category 1. (c) Category 2. (d) Category 3. (e) Category 4. (f) Category 5. Two vertical lines indicate the starting years of aircraft reconnaissance (1944) and satellite observation (1966), and this is the same for all subsequent figures. 
characterized by a relative over-representation for the wind speed range mainly corresponding to Categories 1-2 TCs and under-representation for Categories 4-5 TCs wind speeds. However, the margin of these differences is slightly smaller than for the complete tracks of these same storms as analyzed above. Other features, such as very low frequencies within the windspeed range of 60-70 knots and the change from relative over- to under-representation at windspeed range of $100-110$ knots, are persistent at each geographical level of analysis.

\section{Discussion and implications}

\subsection{Lack of reliability in the early historical record}

For each of the three levels of analysis described above, the distribution of wind speeds during 1851-1943 is significantly different from those of the last six decades $(p<0.001$, for all pairs of Pearson's Chi-square goodness-of-fit tests). Sensitivity analyses undertaken by randomly moderating all wind speeds by \pm 5 or zero knots confirm that the observed differences cannot be attributed to an artefact of binning windspeeds into 10 knot categories. Even for the supposedly best quality subset (the landfalling segments), the average annual number of landfalling segments at extreme TC wind speeds jumps from 0.140 , for the 93-year period spanning 1851 to 1943 , to 0.308 over the 1944-2008 period. The apparent incompleteness of the HURDAT database in respect to the relative paucity of Categories 4 and 5 TCs in the early historical record does not seem to have been widely noted.

The early historical record of the HURDAT has been subject to regular revisions (Landsea et al., 2004, 2008; HURDAT Re-Analysis Project updates website: http://www.aoml.noaa.gov/hrd/data_sub/re_anal.html).

Many studies (e.g. Landsea et al., 2004, 2008, 2009; Vecchi and Knutson, 2008; Chang and Guo, 2007) have examined overall TCs undercounts and/or windspeed estimate variations for the early historical period. Our results in relation to windspeed frequency shifts (both over- and under-estimates) specific to separate 10-knot windspeed intervals (Fig. 1) and TCs counts for each of the Saffir-Simpson Hurricane Categories, especially on extreme TCs (Fig. 2) provide yet further complementary information to better diagnose and quantify systematic biases and random errors in the HURDAT. In the latest revision of HURDAT, 1924 was the first year with a Category $5 \mathrm{TC}$, but if one considers ambiguous storms, as documented in the HURDAT metadata, and that estimates for the early record were conservative (Landsea et al., 2008), earlier Category 5 events may yet be identified.

On the other hand, wind speed distributions over the recent two, four and six decades display little structural change across three geographical scales (Fig. 1b, d, and f). The same conclusions follow if the time series is sub-divided by 30-year windows (Fig. 3a) or after sub-divisions based upon (a)

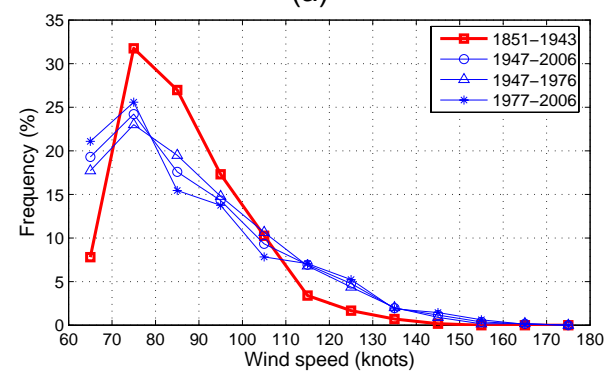

(b)

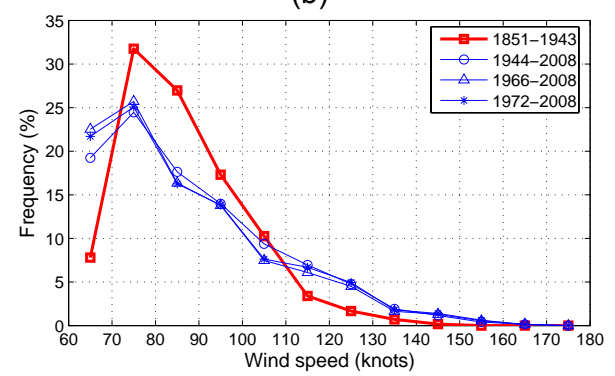

(c)

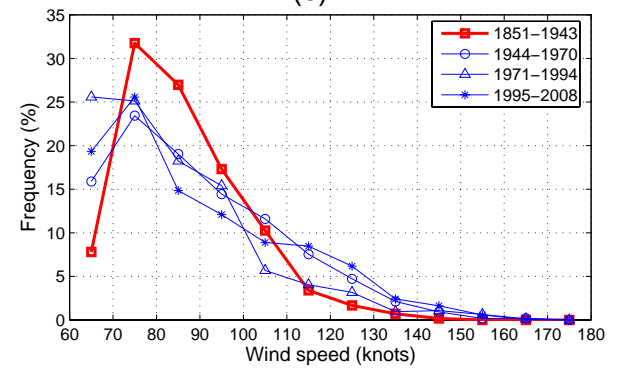

Fig. 3. Wind speed distributions of all segments (Categories 1-5 wind speeds, 1851-2008) of all Atlantic basin TCs under various time periods: (a) 30-year cycles since 1947. (b) Since aircraft reconnaissance began in 1944, geostationary satellite monitoring in 1966, and the use of the Dvorak technique in 1972. (c) Multidecadal cycles of differing TC activity since 1944: one generally low TC activity during 1971-1994; two active periods during 1944-1970 and since 1995 . The wind speed distribution curve for the early historical period 1851-1943 is also superimposed for easier comparisons.

the introduction of different measurement technologies (i.e. since aircraft reconnaissance began in 1944, geostationary satellite monitoring in 1966 and the use of the Dvorak intensity estimation technique in 1972) (Fig. 3b). These varying time periods provide consistent analyses that are unbiased by multidecadal cycles of differing TC activity since 1944 (Goldenberg et al., 2001): generally low TC activity during 1971-1994 and elevated activity during 1944-1970 and since 1995. In fact, wind speed frequencies of the early historical record lie outside the upper and lower range of those derived from the two active and one low multidecadal cycles, except for the wind speed range of 100-110 knots (Fig. 3c). 
Collectively, these results suggest that the differences between the earlier and post-1944 portions of the data record that are persistent across the different geographical levels investigated here are likely the consequence of instrumental and observational deficiencies that have already been well documented (e.g. Landsea, 2007). As discussed elsewhere, the accuracy and reliability of earlier wind record has serious implications for long-term trend analysis (e.g. Trenberth and Shea, 2006; Mann and Emanuel, 2006; Holland and Webster, 2007) and for examination of the possible role of Global Climate Change in influencing the frequency and intensity of tropical cyclones.

\subsection{Implication for hurricane loss modeling}

The shortcomings revealed in the early record also have implications for hurricane loss modeling (Pielke et al., 1999; Iman et al., 2005; Jagger and Elsner, 2006), where emulation of the spatial-temporal attributes of wind speeds in the historical period is routinely exercised. To the best of our knowledge, proprietary and public hurricane loss models all rely on hurricane attributes drawn from the historical wind record most commonly choosing 1851 or 1900 as starting dates. As shown here, naive use of the longest historical record would seriously underestimate the frequency of Categories 4-5 TCs; in other words, using the longest historical record does not necessarily impart the most reliable representation of the wind speed distribution. Therefore, for insurance or economic loss modeling applications, the period chosen to establish distributions of wind speeds should be critically evaluated. The evidence reported here suggests that the hurricane record of the last six decades or so can be sensibly used to determine the relative distribution of wind speeds.

\subsection{Category 5 TCs and disaggregation of Atlantic basin Power Dissipation Index (PDI)}

From Figs. 1 and 3, wind speed distributions of the various time periods since 1944 in the Category 5 wind speed range show a high degree of conformity, although the absolute frequencies are naturally small. We further investigate this feature now by re-examining the PDI and its disaggregation by Saffir-Simpson wind speed categories (see Figs. 4 and 5). The PDI is defined as the sum of the cube of the maximum sustained wind speeds of the six-hourly track segments accumulated over each TC (Emanuel, 2005). In what follows, we will refer to the PDI in its annual form that is further accumulated over all TCs each season. It is now generally accepted that for the Atlantic basin, an increasing trend in PDI has been present since the 1970s (Fig. 4; also see Emanuel, 2005; Landsea, 2005). If we just restrict our attention to the post-1970 record, then it is evident from Fig. 5 that it is the track segments at tropical storm and Category 3 and 4 wind speed categories that are mainly responsible for this recent

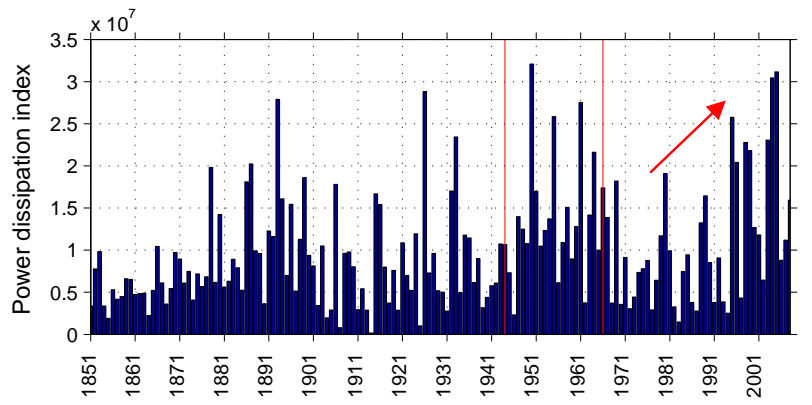

Fig. 4. Atlantic basin Power Dissipation Index (PDI) for tropical storms and Categories 1 to $5 \mathrm{TCs}$, unit $\mathrm{m}^{3} \mathrm{~s}^{-3}$. The arrow indicates an increasing trend in PDI since the 1970s. PDI values for the early historical record are included for the sake of completeness.

upwards trend in PDI, rather than those at Category 5 wind speed category (Fig. 5f). It is not possible to say whether or not this trend will persist long-term.

Figures 6 and 7 examine the contributing components of PDI: the maximum sustained winds, the duration and the number of track segments at different wind speed ranges. (The number of track segments is equivalent to the total duration since each segment represents a six-hour interval duration.) Once again since the 1970s, no upward trend exists in the average maximum wind speed of Category 5 track segments (Fig. 6f) or in their total duration (Fig. 7f). In comparison, for track segments at tropical storm and Category 3 and 4 wind speed categories, their total hours since 1970s have increased (Fig. 7a, d, and e) while their average maximum wind speeds appear steady (Fig. 6a, d, and e). In summary, irrespective of environmental changes that may have occurred over the past few decades, no clear connection can be established between increasing PDI since the 1970s and the average maximum intensity and total duration of Category 5 wind speeds. High-intensity TCs will make important contributions to the PDI (Emanuel, 2005), but as the empirical examination here has shown, an increase in PDI or an increasing trend in PDI does not necessarily imply stronger and longer occurrences of Category 5 wind speeds. It should be noted that the decomposition of PDI at this segment-specific wind speed level is different from and more explicit than that at TC event level employed by Emanuel (2007).

\subsection{Hurricane loss attribution}

Finally, we turn our discussion from the hazard to consequences in terms of insured or economic losses. It can be argued that wind speeds at landfall are most directly associated with damage to property and other assets at risk, but damage outcomes from TCs are also highly influenced by the spatial variability of wind speed and other physical attributes of the system, as well as associated hazards such as storm surge and flooding. Even more important are variables 


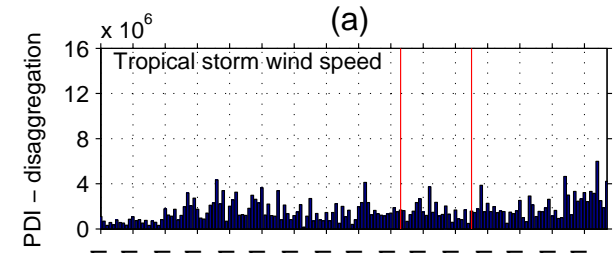

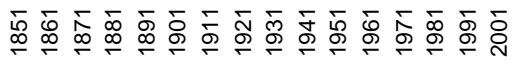
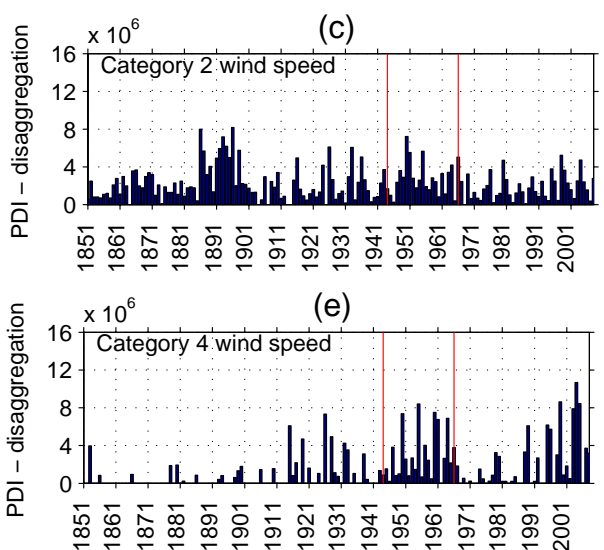

Year

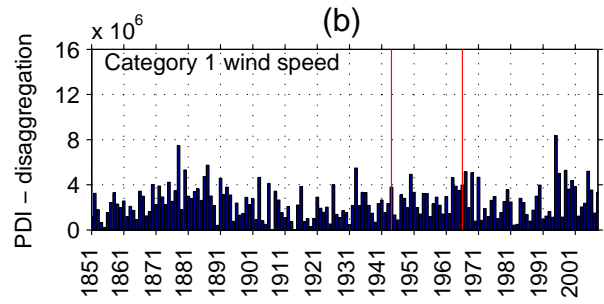

(d)
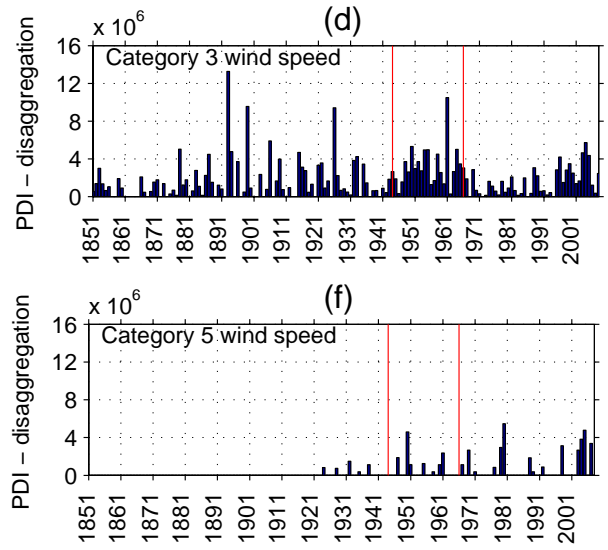

Year

Fig. 5. Atlantic basin Power Dissipation Index disaggregated by track segments of different wind speeds that are defined by the SaffirSimpson Hurricane categories, unit $\mathrm{m}^{3} \mathrm{~s}^{-3}$. (a) Segments at tropical storm wind speeds. (b) Segments at Category 1 wind speeds. (c) Segments at Category 2 wind speeds. (d) Segments at Category 3 wind speeds. (e) Segments at Category 4 wind speeds. (f) Segments at Category 5 wind speeds.

(a)

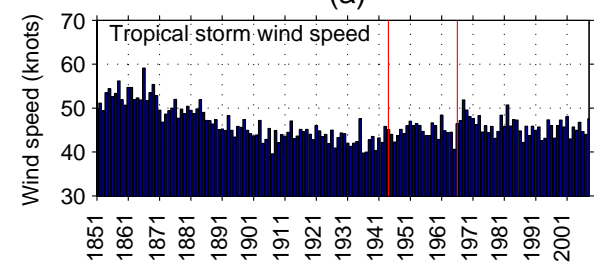

(c)

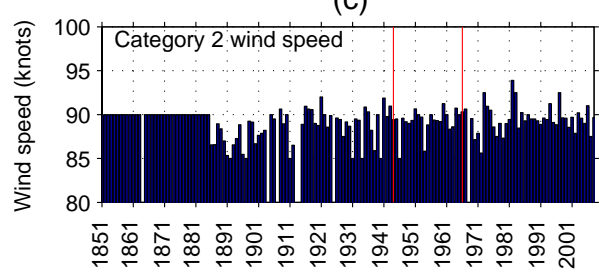

(e)

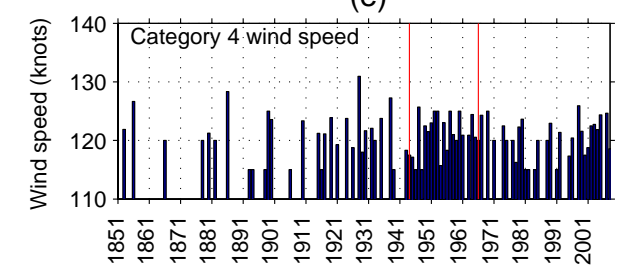

Year (b)

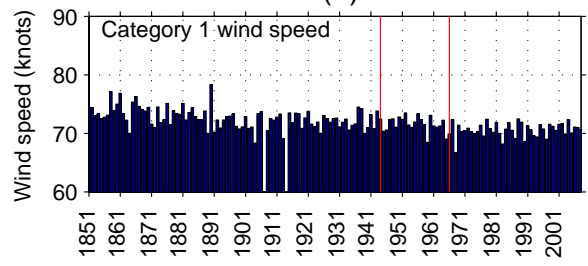

(d)

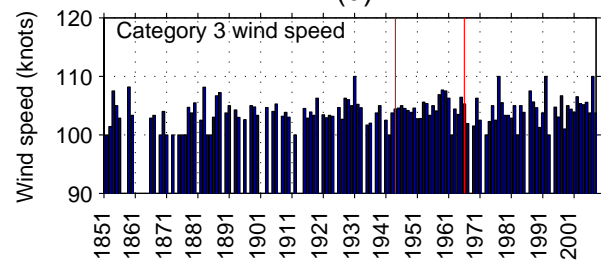

(f)

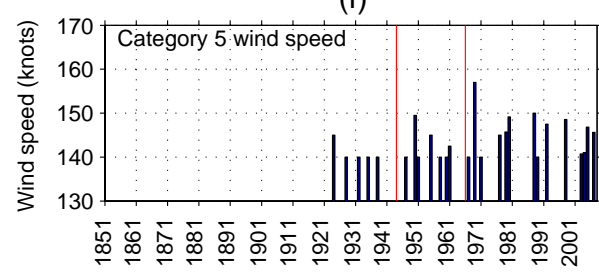

Year

Fig. 6. Average maximum wind speed of track segments. (a) Segments at tropical storm wind speeds. (b) Segments at Category 1 wind speeds. (c) Segments at Category 2 wind speeds. (d) Segments at Category 3 wind speeds. (e) Segments at Category 4 wind speeds. (f) Segments at Category 5 wind speeds. 
(a)

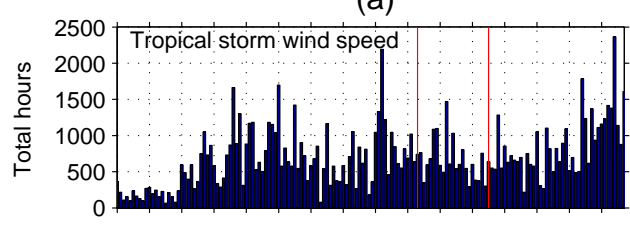

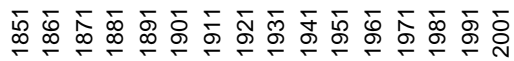

(c)

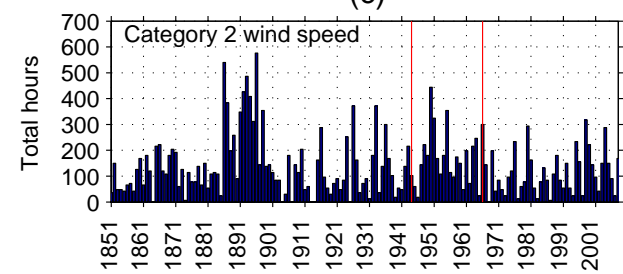

(e)

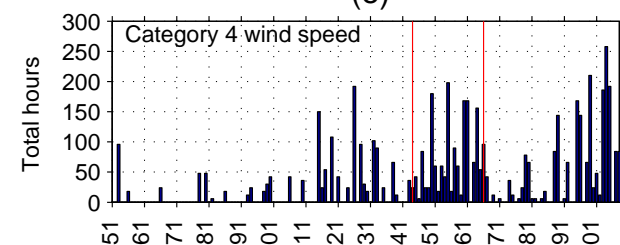

店

Year (b)

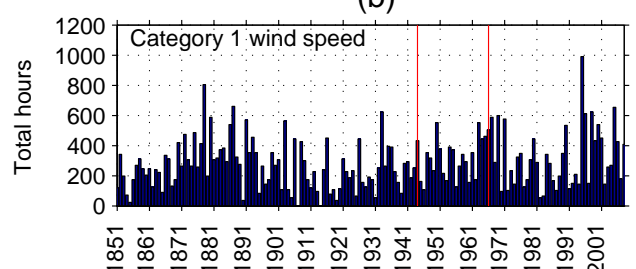

(d)

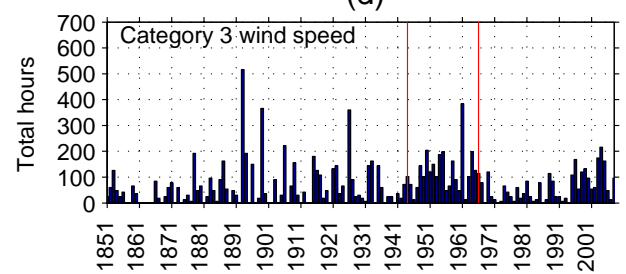

(f)

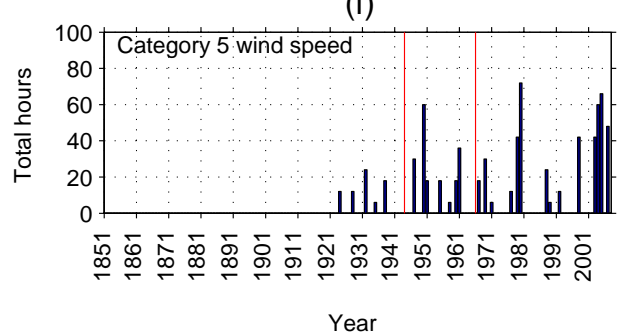

Fig. 7. Total hours for track segments of different wind speeds as defined by Saffir-Simpson Hurricane categories. (a) Segments at tropical storm wind speeds. (b) Segments at Category 1 wind speeds. (c) Segments at Category 2 wind speeds. (d) Segments at Category 3 wind speeds. (e) Segments at Category 4 wind speeds. (f) Segments at Category 5 wind speeds.

such as the density of population and housing with respect to TC tracks (Pielke and Landsea, 1998) and the quality of construction (Crompton and McAneney, 2008). Focusing on the past six decades, we observe no sustained upward trends in wind speed distributions (Figs. 1 and 3), the mean wind speed at landfall or the annual frequency of occurrence of landfalling segments (Fig. 8). (Note that this annual frequency is specific to landfalling segments and different from the annual frequency of landfalling events since some events have multiple landfalling segments, e.g. in 2005 Hurricane Katrina made landfall in both South Florida and Louisiana.) This being the case, the dramatic increases in total economic and insured losses from TCs, which have been manifest over the past six decades, indicates that the increasing losses must be attributed to the factors other than wind speed alone. This is in accord with recent studies (Pielke, 2005; Pielke et al., 2008; Crompton and McAneney, 2008), which demonstrate the importance of demographic changes in driving the increasing economic cost of hurricane losses. The reader is reminded that this attribution analysis of losses differs from our previous examination of the hazard vis-à-vis TC wind speed distribution changes and their possible causes.
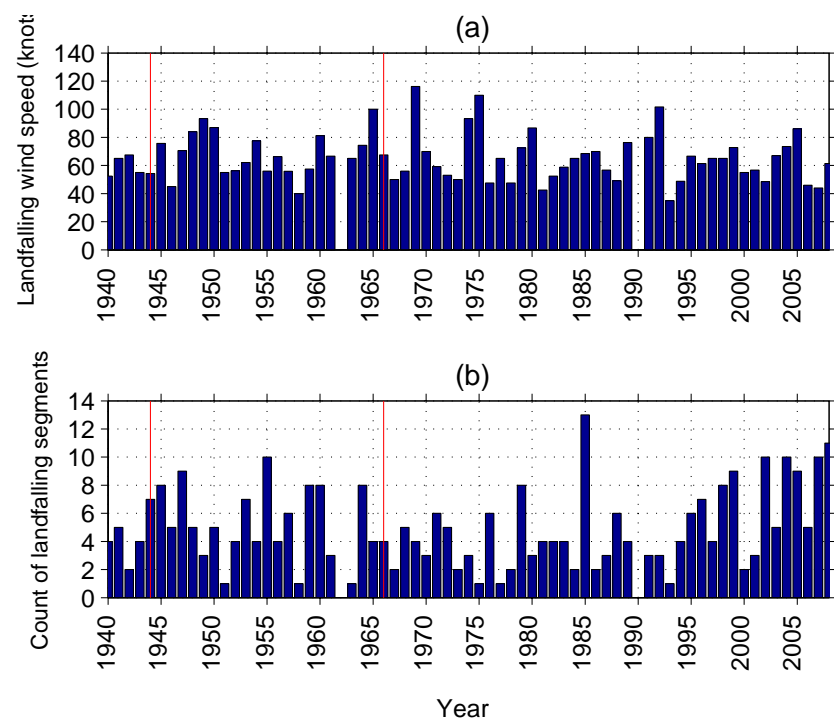

Fig. 8. Average annual statistics for US landfalling segments of tropical storms and hurricanes since 1940. (a) Landfalling wind speed. (b) Number of landfalling segments. Note that TC landfalls occurred in 1962 and 1990 but the landfalling segments had wind speeds less than the tropical storm strength. 


\section{Conclusions}

Our investigation stresses TC track segments and hinges on historical observational data and statistical analyses of this data at different geographical levels and time periods. In this way it is complementary to other studies using climate models. We present long-term, time-series results that have deliberately not been subjected to aggregation or multi-year filtering.

The quality of observational data is central to the ongoing debate between a warming climate and consequences for TC frequency and intensities. Our analyses show clear, anomalous differences in the wind speed distributions between the early historical period and the very recent six decades. While these differences cannot unequivocally exclude a possible Global Climate Change cause, we suggest that data quality issues are more plausible.

An enormous challenge lies ahead for recovering reliable wind estimates in the early historical record, especially for highly dynamic and short-lived extreme TCs. The counting of events by Saffir-Simpson Hurricane categories is determined by threshold wind speeds, and if the wind estimates are themselves unreliable, how can derivative statistics be trusted sufficiently for long-term trend analysis? It is timely to recognise that using the early historical record will inevitably involve some irreducible uncertainties and "fixing" these may not be possible and that more physically-based models are needed to help resolve the data impasse. Conclusions drawn from scientific and insurance applications using the inherently lower-quality components of the record should be treated with caution.

Acknowledgements. The authors thank Roger Pielke Jr., Patrick Fitzpatrick, Ryan Crompton, Rade Musulin, Matthew Mason and anonymous reviewers for their helpful comments. We acknowledge the NOAA National Hurricane Center for providing updated HURDAT database analysed in this study.

Edited by: A. Mugnai

Reviewed by: P. Fitzpatrick and two anonymous referees

\section{References}

Blake, E. S., Rappaport, E. N., and Landsea, C. W.: The Deadliest, Costliest, And Most Intense United States Tropical Cyclones From 1851 To 2006 (And Other Frequently Requested Hurricane Facts), NOAA Technical Memorandum NWS TPC-5, National Hurricane Center, Miami, Florida, 2007.

Chang, E. K. M. and Guo, Y.: Is the number of North Atlantic tropical cyclones significantly underestimated prior to the availability of satellite observations?, Geophys. Res. Lett., 34, L14801, doi:10.1029/2007GL030169, 2007.

Chenoweth, M. and Divine, D.: A document-based 318year record of tropical cyclones in the Lesser Antilles, 1690-2007, Geochem. Geophy. Geosy., 9, Q08013, doi:10.1029/2008GC002066, 2008.
Crompton, R. P. and McAneney, K. J.: Normalised Australian insured losses from meteorological hazards: 1967-2006, Environ. Sci. Policy, 11, 371-378, 2008.

Emanuel, K., Sundararajan, R., and Williams, J.: Hurricanes and global warming: Results from downscaling IPCC AR4 simulations, B. Am. Meteorol. Soc., 89, 347-367, 2008.

Emanuel, K.: Environmental factors affecting tropical cyclone power dissipation, J. Climate, 20, 5497-5509, 2007.

Emanuel, K.: Increasing destructiveness of tropical cyclones over the past 30 years, Nature, 436, 686-688, 2005.

Goldenberg, S. B., Landsea, C. W., Mestas-Nunez, A. M., and Gray, W. M.: The recent increase in Atlantic hurricane activity: Causes and implications, Science, 293, 474-479, 2001.

Grossi, P. and Kunreuther, H. (Eds.): Catastrophe Modeling: A New Approach to Managing Risk, Springer, New York, 2005.

Holland, G. J. and Webster, P. J.: Heightened tropical cyclone activity in the North Atlantic: natural variability or climate trend?, Philos. T. R. Soc. A, 365(1860), 2695-2716, doi:10.1098/rsta.2007.2083, 2007.

Hoyos, C. D., Agudelo, P. A., Webster, P. J., and Curry, J. A.: Deconvolution of the factors contributing to the increase in global hurricane intensity, Science, 312, 94-97, 2006.

Iman, R. L., Johnson, M. E., and Watson Jr., C. C.: Uncertainty analysis for computer model projections of hurricane losses, Risk Anal., 25, 1299-1312, 2005.

Jagger, T. H. and Elsner, J. B.: Climatology models for extreme hurricane winds near the United States, J. Climate, 19, 32203236, 2006.

Jarvinen, B. R., Neumann, C. J., and Davis, M. A. S.: A Tropical Cyclone Data Tape For the North Atlantic Basin, 1886-1983: Contents, Limitations, and Uses, NOAA Technical Memorandum NWS NHC-22, National Hurricane Center, Miami, Florida, 1984.

Knutson, T. R., Sirutis, J .J., Garner, S. T., Vecchi, G. A., and Held, I. M.: Simulated reduction of Atlantic hurricane frequency under twenty-first-century warming conditions, Nature Geosci., 1, 359-364, doi:10.1038/ngeo202, 2008.

Kossin, J. P., Knapp, K. R., Vimont, D. J., Murnane, R. J., and Harper, B. A.: A globally consistent reanalysis of hurricane variability and trends, Geophys. Res. Lett., 34, L04815, doi:10.1029/2006GL028836, 2007.

Landsea, C. W.: Counting Atlantic tropical cyclones back to 1900 , Eos, 88, 197-202, 2007.

Landsea, C. W., Anderson, C. A., Charles, N., Clark, G., Dunion, J., Fernandez-Partagas, J., Hungerford, P., Neumann, C., and Zimmer, M.: The Atlantic hurricane database re-analysis project: Documentation for 1851-1910 alterations and additions to the HURDAT database, in: Hurricanes and Typhoons: Past, Present and Future, edited by: Murnane, R. J. and Liu, K. B., Columbia Univ. Press, New York, 177-221, 2004.

Landsea, C. W., Glenn, D. A., Bredemeyer, W., Chenoweth, M., Ellis, R., Gamache, J., Hufstetler, L., Mock, C., Perez, R., Prieto, R., Sanchez-Sesma, J., Thomas, D., and Woolcock, L.: A reanalysis of the 1911-20 Atlantic hurricane database, J. Climate, 21, 2138-2168, 2008.

Landsea, C. W.: Hurricanes and global warming, Nature, 438, E1113, 2005.

Landsea, C. W., Harper, B. A., Hoarau, K., and Knaff, J. A.: Can we detect trends in extreme tropical cyclones?, Science, 313, 452- 
454, 2006.

Landsea, C. W., Vecchi, G. A., Bengtsson, L., and Knutson, T. R.: Impact of duration thresholds on Atlantic tropical cyclone counts, J. Climate, doi:10.1175/2009JCLI3034.1, in press, 2009.

Liu, K. B.: Uncovering prehistoric hurricane activity, Am. Sci., 95, 126-133, 2007.

Lonfat, M., Boissonnade, A., and Muir-Wood, R.: Atlantic basin, U.S. and Caribbean land-fall activity rates over the 2006-2010 period: an insurance industry perspective, Tellus A, 59, 499-510, 2007.

Mann, M. and Emanuel, K.: Atlantic hurricane trends linked to climate change, Eos, 87, 233-241, 2006.

Nyberg, J, Malmgren, B. A., Winter, A., Jury, M. R., Kilbourne, K. H., and Quinn, T. M.: Low Atlantic hurricane activity in the 1970 s and 1980 s compared to the past 270 years, Nature, 447, 698-702, 2007.

Pielke Jr., R. A., Gratz, J., Landsea, C. W., Collins, D., Saunders, M. A., and Musulin, R.: Normalized hurricane damage in the United States: 1900-2005, Natural Hazards Review, 9, 29-42, 2008.

Pielke Jr., R. A.: Are there trends in hurricane destruction?, Nature, 438, E11, 2005.

Pielke Jr., R. and Landsea C.: Normalised hurricane damages in the United States, Weather Forecast., 13, 621-631, 1998.

Pielke Jr., R., Landsea, C., Mayfield, M., Laver, J., and Pasch, R.: Hurricanes and global warming, B. Am. Meteorol. Soc., 87, 1571-1575, 2005.
Pielke Jr., R., Landsea, C., Musulin, R., and Downton, M.: Evaluation of catastrophe models using a normalized historical record: Why it is needed and how to do it, J. Risk Insur., 18, 177-194, 1999.

Saunders, M. A. and Lea, A. S.: Large contribution of sea surface warming to recent increase in Atlantic hurricane activity, Nature, 451, 557-560, 2008.

Solow, A. and Beet, A. R.: On the incompleteness of the historical record of North Atlantic tropical cyclones, Geophys. Res. Lett., 35, L11803, doi:10.1029/2008GL033546, 2008.

Swiss Re: Sigma 2/2009, available at: http://www.swissre.com/ sigma, 2009.

Trenberth, K. E. and Shea, D. J.: Atlantic hurricanes and natural variability in 2005, Geophys. Res. Lett., 33, L12704, doi:10.1029/2006GL026894, 2006.

Vecchi, G. A. and Knutson, T. R.: On estimates of historical North Atlantic tropical cyclone activity, J. Climate, 21, 3580-3600, 2008.

Velden, C., Harper, B., Wells, F., Beven II, J. L., Zehr, R., Olander, T., Mayfield, M., Guard, C., Lander, M., Edson, R., Avila, L., Burton, A., Turk, M., Kikuchi, A., Christian, A., Caroff, P., and McCrone, P.: The Dvorak tropical cyclone intensity estimation technique: A satellite-based method that has endured for over 30 years, B. Am. Meteorol. Soc., 87, 1195-1210, 2006.

Watson Jr., C. C. and Johnson, M. E.: Hurricane loss estimation models: opportunities for improving the state of the art, B. Am. Meteorol. Soc., 85, 1713-1726, 2004.

Webster, P. J., Holland, G. J., Curry, J. A., and Chang, H.-R.: Changes in tropical cyclone number, duration, and intensity in a warming environment, Science, 309, 1844-1846, 2005. 